\title{
Comparisons among different Types of Single Phase Step Down AC to DC Converters
}

\author{
Adnan Mohammad \\ Department of Electrical and \\ Electronic Engineering \\ American International \\ University-Bangladesh (AIUB) \\ Dhaka, Bangladesh
}

\author{
Abdullah Al Manzur \\ Department of Electrical and \\ Electronic Engineering \\ American International \\ University-Bangladesh (AIUB) \\ Dhaka, Bangladesh
}

\author{
Ashique lbni Aziz \\ Department of Electrical and \\ Electronic Engineering \\ American International \\ University-Bangladesh (AIUB) \\ Dhaka, Bangladesh
}

\begin{abstract}
This paper represents a comparative study among different types of existing single phase AC to DC step down converter. Their performances and outputs have been analyzed depending on their equations. Different parameters such as voltage gain, harmonic contents in input current, parameters of changing output voltage are compared among three different existing single phase $\mathrm{AC}$ to $\mathrm{DC}$ converters. This research also highlights the advantages and drawbacks of these converters. Simulations of the converters are performed using MATLAB/SIMULINK and PSIM.
\end{abstract}

\section{Keywords}

Converter; comparisons; step down; single stage.

\section{INTRODUCTION}

AC to DC converter is defined as rectifier [1-3]. The main power supply system is alternating in nature. Rectification action is required to obtain DC supply from the main power supply which is sinusoidal. In many applications such as battery charging, formation of electromagnet, television, computers and etc smooth DC signal is required with specified level. Generally step down action is used to get a lower voltage from the main supply system [4]. Ripple in current and voltage waveforms are reduced by using a low pass filter [4-6]. Different techniques are used to get the desired form of stepped down DC signal from the main power system.

One of the methods uses transformer to step down the AC voltage and rectifier to get unidirectional signal [7]. Another method uses rectifier and DC chopper to step down DC voltage [7-11]. Controlled rectifier uses SCR which is operated using gate pulses at different delay angle. Several research works on single stage direct ac to dc step up and down conversion has been done [7]. Size is always an important issue for designing a converter [12]. One circuit of single stage AC to DC direct stage step down conversion is analyzed in this paper to compare with other methods.

Mathematical equations and operations of different converters are analyzed in section 2. Flexibility of operation of different converters is analyzed based on the numbers of stages and some parameters such as total harmonic distortion (THD) of input current, input power factor and etc. Simulations are performed in section 3 using MATLAB/SIMULINK and PSIM.

\section{OPERATIONS OF DIFFERENT STEP DOWN AC TO DC CONVERTERS}

One of the traditional methods uses transformer and rectifier to get stepped down DC voltage from main AC supply. Fig. 1 shows the method which includes transformer and rectifier. Transformer is used to step down the AC supply voltage and rectifier is used to get DC voltage. A filter is used to get smooth DC voltage.

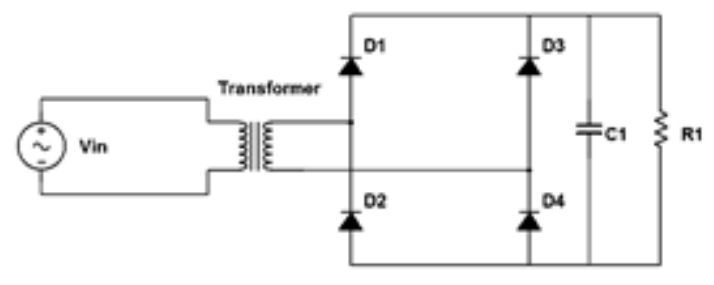

Fig 1: Use of transformer and rectifier to get a step down DC voltage from main AC supply

In this case there are two stages which reduce the efficiency due to power losses in two stages. Transformer has core loss which is divided into two types. One of the transformer losses is termed as eddy current loss and another one is hysteresis loss [13]. In the rectifier the losses take place in diodes. The output voltage across R1 for this case can be expressed as,

$$
V o=\frac{2^{*} V \sec (p)}{\pi}
$$

$V \sec (p)$ is the peak value of secondary voltage of the transformer.

$$
n=\frac{V \sec (p)}{\operatorname{Vpri}(p)}
$$

$n$ is the ratio of primary voltage to secondary voltage of the transformer. For a step down transformer the value of $n$ is less than one. $\operatorname{Vpri}(p)$ represents the peak value of the primary voltage of the transformer or main AC supply. Combining (1) and (2),

$$
\operatorname{Vo}=\frac{2 * n * \operatorname{Vpri}(p)}{\pi}
$$




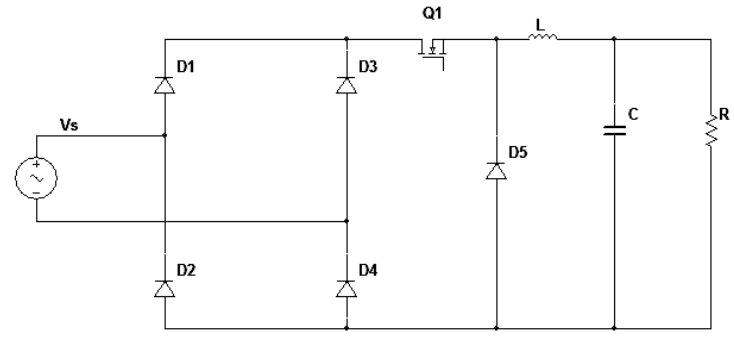

Fig 2: Use of rectifier and DC chopper to get a step down DC voltage from main AC supply

In this method two power electronic converters are added to get rectified stepped down voltage. Fig. 2 shows the process. A rectifier circuit provides unidirectional voltage from AC main supply. DC chopper is used to get a lower level of DC voltage. Switching of the DC converter is controlled to vary the level of DC voltage. In this scheme there is no transformer so the size will be smaller than the previous method shown in Fig.1. The presence of two stages will be a reason of power losses of the converter. The average value of output voltage of single phase full wave bridge rectifier is,

$$
\operatorname{Vo}(\text { rect })=\frac{2 * \operatorname{Vin}(p)}{\pi}
$$

$\operatorname{Vin}(p)$ is the peak value of voltage of AC main supply. The output of step down DC chopper is,

$$
\text { Vo }(\text { chopper })=D * \operatorname{Vin}
$$

Vo(chopper) is the output of the DC chopper, $D$ is the duty cycle defined as the ratio of the pulse width of the switching pulse to the switching period and Vin is the input to the DC chopper. From Fig.2 it is seen that, the output of the rectifier acts as an input to the DC chopper. Combining (4) and (5),

$$
\operatorname{Vo}=\frac{2 * D * \operatorname{Vin}(p)}{\pi}
$$

Previous methods are based on two stages which increase the power loss and size as well. This two desired action can be performed using single stage converter.

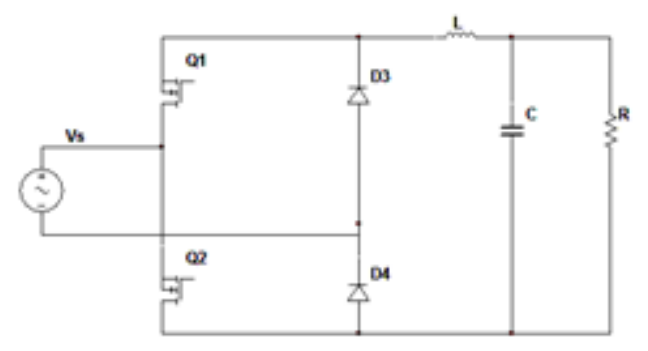

Fig 3: A single stage stepped down rectification system

In this case the diodes contribute in rectification and the switches control the value of output voltage. The output voltage can be easily set to a desired lower value using different pulse width modulations on switches. The output of this converter can be expressed as,

$$
V(\text { average })=\frac{2 * V p}{\pi} * \operatorname{Sin} \frac{\pi D}{2 N} * \sum_{n=1}^{N} \operatorname{Sin} \frac{\pi}{N}\left(n-1+\frac{D}{2}\right)
$$

$V($ Average $)$ is the average value of output voltage, $V p$ is the peak value of input sinusoidal wave, $N$ is the numbers of pulses in each half cycle of the input sinusoidal wave, $n$ is integer and $D$ is the duty cycle.

\section{COMPARISONS AND SIMULATION}

The outputs of three different converters are expressed in (3),(6), and (7).

From (3) it is seen that for getting desired low DC voltage the ratio of transformer winding can be changed. For getting a variable low DC voltage from main AC supply, this scheme will not be that much suitable due to the uneasiness of changing the ratio of transformer windings.

Equation (6) is for the scheme which contains rectifier and DC chopper. In this case only duty cycle is the variable to change the output voltage of the converter. Varying duty cycle is easier than changing the ratio of transformer windings. So this process is better if compared with the first method. This converter requires a control circuit for pulse width modulation of the switching signal.

From (7) it is seen that the average output voltage is dependent on duty cycle and numbers of pulses. It can be stated that only variable is duty cycle to change the output voltage. This method has only one stage which indicates reduced power losses in the converter if compared with the previous processes. Requirement of additional control circuit is obvious in this process.

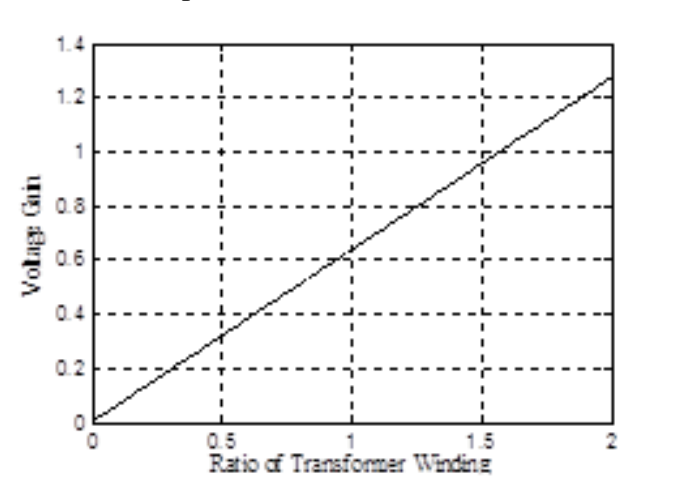

Fig 4: Voltage gain characteristic of AC to DC step down conversion system using transformer and rectifier

Fig. 4 illustrates the voltage gain characteristic of AC to DC step down conversion system using transformer and rectifier. The analysis is based on (3). The voltage gain of this process is totally dependent on the ratio of transformer winding. It is also clear that step up operation is possible in this method.

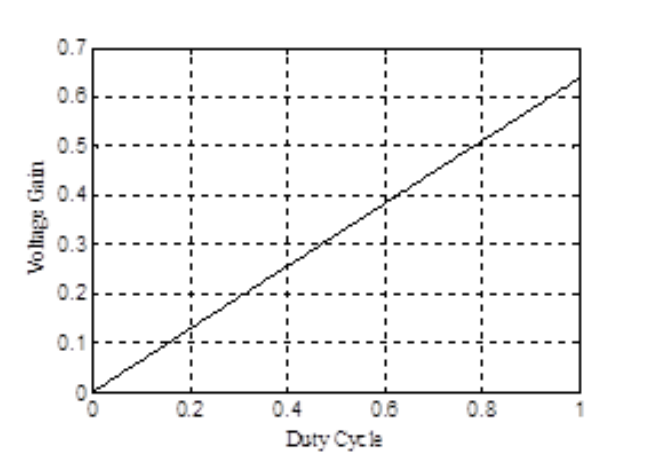

Fig 5: Voltage gain characteristic of AC to DC step down conversion system using rectifier and buck converter 
Fig. 5 illustrates the voltage gain characteristic of AC to DC step down conversion system which consists of rectifier and buck converter. The voltage gain of this process is totally dependent on the duty cycle of switching pulses. Maximum value of duty cycle is one. Step down action is not possible in this process. The maximum voltage gain in this method is 0.6366 or $63.66 \%$.

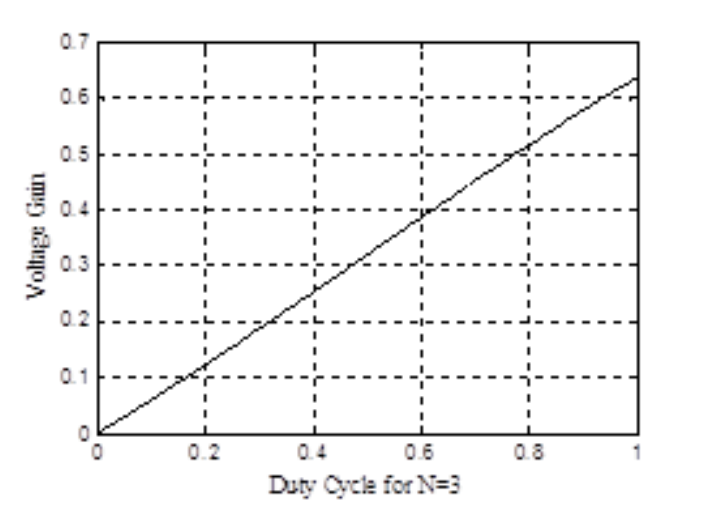

Fig 6: Voltage gain characteristic of the single stage AC to DC step down conversion process

Fig. 6 shows the voltage gain characteristic of the single stage AC to DC step down conversion process. It is based on (7) and $\mathrm{N}=3$. The voltage gain of this process is dependent on the duty cycle of the switching pulses. Duty cycle will never be greater than one. The maximum gain of this scheme is same as previous scheme but it contains one stage only.

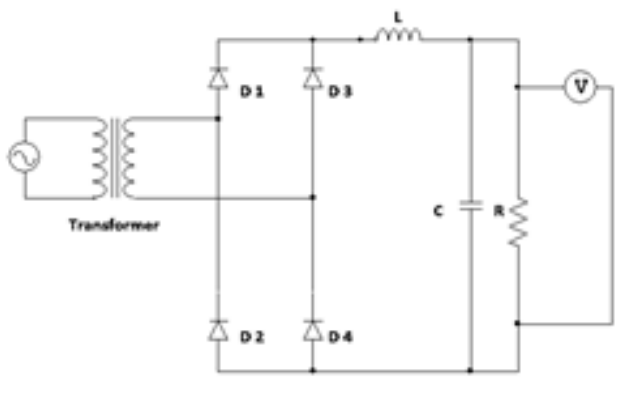

Fig 7: Simulation of transformer and rectifier method of AC-DC step down process in PSIM (Method I)

Fig. 7 shows the transformer and rectifier method (Method I) of AC-DC step down process. The transformer steps down the AC voltage and the diodes rectify the voltage available secondary winding. The ratio of secondary winding turn numbers to primary winding turn numbers is 0.0606 . The peak of input sine wave is $311 \mathrm{~V}$ and the output is around 12 $\mathrm{V}$. The output voltage is derived from (3).

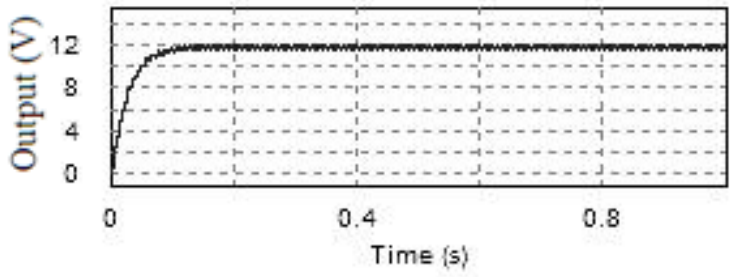

Fig 8: Output of transformer and rectifier method (Method I) of AC-DC step down process in PSIM

The output can be only changed depending on the winding ratio of transformer. The output voltage of Method I is shown in fig. 8 .

\section{Table I. Simulation Parameters for Method I}

\begin{tabular}{|c|c|}
\hline Parameters & Value \\
\hline $\begin{array}{c}\text { Input Voltage } \\
(\text { Vs) }\end{array}$ & $220 \mathrm{~V}(\mathrm{rms})$ \\
\hline Turn Ratio (n) & 0.0606 \\
\hline L (filter) & $350 \mathrm{mH}$ \\
\hline $\mathrm{C}$ (filter) & $250 \mathrm{uF}$ \\
\hline Output Load (R) & $12 \Omega$ \\
\hline Output Voltage & $12 \mathrm{~V}$ \\
\hline Output Power & $12 \mathrm{~W}$ \\
\hline
\end{tabular}

Table I shows the parameters which are used in the simulation. The output power for the converter is $12 \mathrm{~W}$. Filter inductor and capacitor are used to reduce the ripple in current and output voltage.

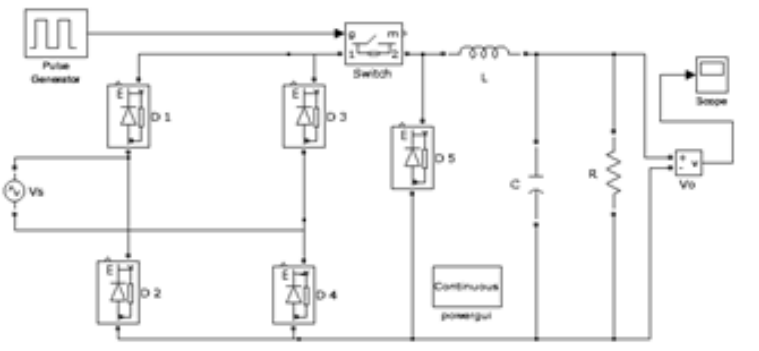

Fig 9: Simulation of rectifier and buck chopper method of step down action in MATLAB/SIMULINK (Method II)

Fig. 9 shows the circuit of rectifier and buck chopper method (Method II) of step down action. The first stage rectifies and the second stage controls the value of output DC voltage depending on the duty cycle (D).



Fig 10: Output of rectifier and buck chopper method (Method II) of step down action in MATLAB/SIMULINK

Fig. 10 show the output voltage for fig. 9. This is simulated from (6). The peak of input voltage is $311 \mathrm{~V}$, duty cycle is $6.06 \%$ and output is around $12 \mathrm{~V}$.

Table II. Simulation Parameters for Method II

\begin{tabular}{|c|c|}
\hline Parameters & Value \\
\hline Input Voltage (Vs) & $220 \mathrm{~V}(\mathrm{rms})$ \\
\hline Switching Frequency & $1 \mathrm{KHz}$ \\
\hline Duty Cycle & $6.06 \%$ \\
\hline L (filter) & $350 \mathrm{mH}$ \\
\hline C (filter) & $250 \mathrm{uF}$ \\
\hline Output Load (R) & $12 \Omega$ \\
\hline Output Voltage & $12 \mathrm{~V}$ \\
\hline Output Power & $12 \mathrm{~W}$ \\
\hline
\end{tabular}

Parameters for Method III are shown in Table III. The output power for the converter is $12 \mathrm{~W}$. The output voltage is dependent on the duty cycle of the switching pulses. 


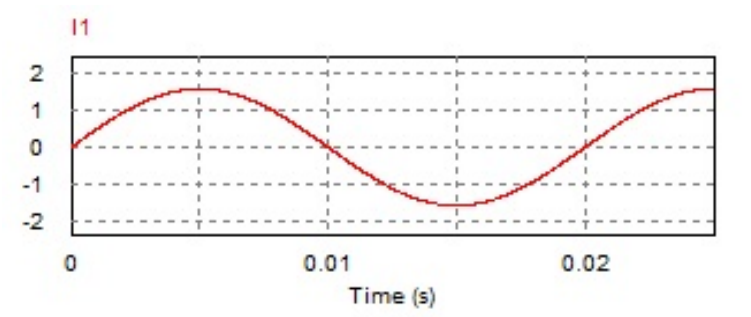

Fig 14: The input current of Method I

Fig. 14 shows the input current of Method I. It is a pure sinusoidal wave with peak value of $1.57 \mathrm{~A}$.

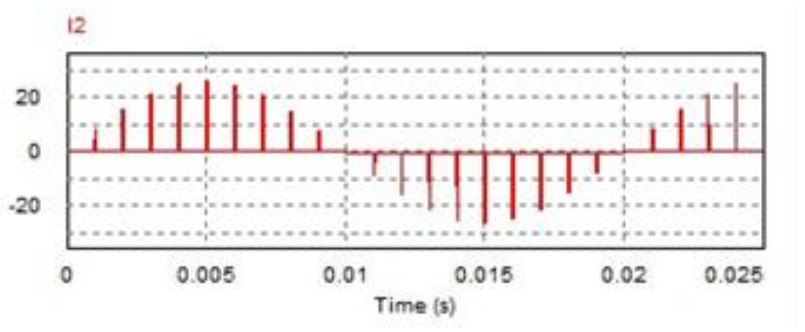

Fig 15: The input current of Method II and III

Fig. 15 shows the input current of Method II and III. It has a fundamental component of $50 \mathrm{~Hz}$. Input current of Method I is a perfect sinusoidal wave of frequency $50 \mathrm{~Hz}$.

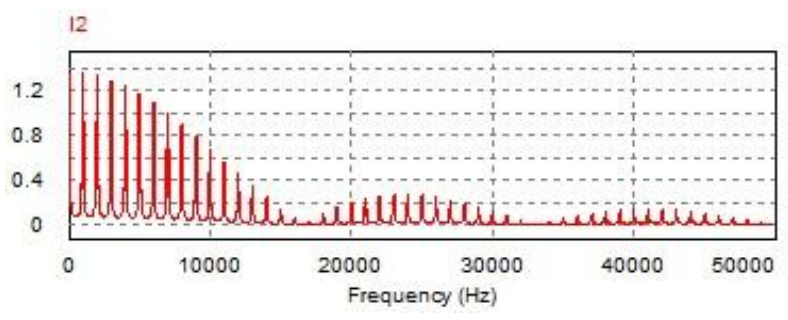

Fig 16: FFT analysis of input current of Method-II and Method-III

Fig.16 shows the FFT analysis of input currents of method-II and method-III. From Fig.14 and Fig.15 it is seen that, the harmonic contents in input current of method-II and methodIII are higher than method-I. These harmonic contents in the current can be controlled using different PWM on converter`s switching [14]. The FFT analysis on input current is performed excluding the filter circuits ( $\mathrm{L}$ and $\mathrm{C}$ ) of the converters.

Table IV. Comparisons Of The Converters

\begin{tabular}{|c|c|c|c|}
\hline Circuit & Method I & $\begin{array}{c}\text { Method } \\
\text { II }\end{array}$ & Method III \\
and rectifier & $\begin{array}{c}\text { Rectifier } \\
\text { and DC } \\
\text { chopper }\end{array}$ & $\begin{array}{c}\text { Modified } \\
\text { rectifier with } \\
\text { switches }\end{array}$ \\
\hline $\begin{array}{c}\text { Parameter to } \\
\text { change the } \\
\text { output }\end{array}$ & $\begin{array}{c}\text { Winding } \\
\text { ratio of } \\
\text { transformer } \\
\text { (n) }\end{array}$ & $\begin{array}{c}\text { Duty } \\
\text { cycle (D) }\end{array}$ & $\begin{array}{c}\text { Duty Cycle } \\
\text { (D) }\end{array}$ \\
\hline Stage & Two & Two & One \\
\hline Size & Larger & $\begin{array}{c}\text { Smaller } \\
\text { than } \\
\text { Method I }\end{array}$ & Smaller \\
\hline $\begin{array}{c}\text { Control } \\
\text { Circuit }\end{array}$ & Not required & Required & Required \\
\hline $\begin{array}{c}\text { Flexibility of } \\
\text { getting }\end{array}$ & Not flexible & flexible & flexible \\
\hline
\end{tabular}

\begin{tabular}{|c|c|c|c|}
\hline $\begin{array}{c}\text { variable DC } \\
\text { output voltage }\end{array}$ & Possible & $\begin{array}{c}\text { Not } \\
\text { possible }\end{array}$ & Not possible \\
\hline $\begin{array}{c}\text { Possibility of } \\
\text { operation }\end{array}$ & Maximum \\
voltage gain & $\begin{array}{c}\text { Depends on } \\
\text { winding ratio }\end{array}$ & $63.66 \%$ & $63.66 \%$ \\
\hline $\begin{array}{c}\text { Harmonic } \\
\text { contents in } \\
\text { input current }\end{array}$ & $\begin{array}{c}\text { Only } \\
\text { fundamental } \\
\text { components } \\
\text { (Desired) }\end{array}$ & $\begin{array}{c}\text { Higher } \\
\text { than } \\
\text { method-I } \\
\text { (Not } \\
\text { desired) }\end{array}$ & $\begin{array}{c}\text { Higher than } \\
\text { method-I } \\
\text { (Not } \\
\text { desired) }\end{array}$ \\
\hline $\begin{array}{c}\text { Total } \\
\text { Harmonic } \\
\text { Distortion } \\
\text { (THD) }\end{array}$ & 0 & 3.96 & 3.96 \\
\hline $\begin{array}{c}\text { Input Power } \\
\text { Factor }\end{array}$ & 1 & 0.2403 & 0.2403 \\
\hline
\end{tabular}

Table IV represents the comparisons among three converters based on different factors. Some comparisons will be explained broadly for better understanding.

\subsection{Circuit}

Method I uses one transformer, four diodes, filter inductor and capacitor. There are total seven components in Method I for desired conversion. Method II consists of five diodes, one switches, filter inductor and capacitor. Though there are total eight components in Method II, the weight and size will be reduced if compared with Method I due to elimination of transformer in Method II. The size of Method III is smaller as it only uses four diodes and filter components.

\subsection{Parameter to change the output voltage}

In Method I the output voltage or voltage gain is dependent on the turn ratio of transformer. Center tapped transformer can be used to achieve different gain of this converter. Duty cycle (ratio of ON switch time to switching period) is the key factor to get different levels of output in Method II and III.

\subsection{Control Circuit}

Method II and III require low power electronic control circuit to control the ON-OFF process of switches used in the circuits.

\subsection{Flexibility of getting variable output voltage}

It is very easy to change the duty cycle or ON switch time of switching pulses. This can be performed changing a reference voltage used in control circuits. In case of Method I, changing output voltage is not so flexible because it is not so easy to change the turn ratio of transformer if compared with the techniques of changing duty cycle in Method II and III.

\subsection{Possibility of step up operation}

As previously discussed, the output voltage of Method I is totally dependent on turn ratio of transformer for a specific input voltage. It is possible to make the turn ratio of transformer greater than one (secondary winding having more turn numbers than primary). Using (3), desired turn ratio can be found for step up operation. In case of Method II and III, the output is dependent on duty cycle (D) which will never be greater than one. So, step up operation is not possible in Method II and III. 


\subsection{Harmonic contents in input current}

Input current of Method II and III contains harmonics. Their total harmonic distortion (THD) is quite high in those cases. Method I has harmonic less input current.

\subsection{Input Power Factor}

Input power factor is unity for resistive load in Method I. Method II and III have poor input power factor (0.2403). It is always desired to have high power factor in input side.

\section{CONCLUSION}

In this paper three different existing topologies of single phase step down AC to DC converters are compared based on their output voltage equations, voltage gain, harmonic contents in input current and numbers of components etc. This type of research provides an idea about different ac to dc conversion processes which are extensively used in dc power supply, dc drives, battery charging and etc. Each methods of conversion has some drawbacks and advantages also. Further studies based on these conventional converters can be done to improve the input power factor of the converters, efficiency, cost and etc.

\section{REFERENCES}

[1] M. H. Rashid, "Diode rectifiers," in Power Electronics Circuits, Devices and Applications, 3rd ed. New Delhi, India: Prentice Hall, 2004, pp. 68-120.

[2] Dr. B.R. Gupta, V. Singhal. "Controlled Rectifiers," in Power Electronics, 6th ed. Delhi, India: S.K. Kataria \& Sons, 2010, pp. 125-198.

[3] Dr. P.S. Bimbhra, "Diode Circuits and Rectifiers," in Power Electronics, 5th ed. Daryaganj, New Delhi, India: Khanna Publishers, 2012, pp. 50-131.

[4] T. J. Liang, L. S. Yang, and J. F. Chen, "Analysis and design of a single phase ac/dc step-down converter for universal input voltage," IET Electr Power Appl., vol. 1, no. 5, pp. 778-784, Sep. 2007.

[5] K. Nishimura, K. Hirachi, S. Komiyama, and M. Nakaoka, "Two buck choppers built-in single phase one stage PFC converter with reduced DC voltage ripple and its specific control scheme," in Proc. IEEE Appl. Power Electron. Conf. Expo., 2008, pp.1378-1383.

[6] Dr. P.S. Bimbhra, "Diode circuits and rectifiers," in Power Electronics, 5th ed. Daryaganj, New Delhi, India: Khanna Publishers, 2012, pp. 50-131.

[7] S. Dwari and L. Parsa,"An efficient ac-dc step-up converter for low-voltage energy harvesting," IEEE Trans. Power Electron., vol. 25, no. 8,pp. 2188-2199, Aug. 2010.

[8] M. H. Rashid, "Dc-dc converters," in Power Electronics Circuits, Devices and Applications, 3rd ed. New Delhi, India: Prentice Hall, 2004, pp. 166-224.

[9] S. Sivanagaraju, M. B. Reddy, A.M. Prasad, "Dc choppers," in Power Electronics, 1st ed. New Delhi, India : PHI Learning Private Limited, 2010, pp. 329-455.

[10] Dr. B.R. Gupta, V. Singhal. "Choppers," in Power Electronics, 6th ed. Delhi, India: S.K. Kataria \& Sons, 2010, pp. 246-283.

[11] Dr. P.S. Bimbhra, "Choppers," in Power Electronics, 5th ed. Daryaganj, New Delhi, India: Khanna Publishers, 2012, pp. 380-453.

[12] S. K. Ki and D. D. C. Lu, "Implementation of an efficient transformerless single-stage single-switch ac/dc converter," IEEE Trans. Ind . Electron.,vol. 57, no.12, pp. 4095-4105, Dec. 2010.

[13] S. Hasan, S. Taib, S. Hardi, A. Rahim and A. Shukri, "Core Loss Characteristics Analysis od Power Transformer Under Different Frequencies Excitation," IEEE 7th International Power Engineering and Optimization Conference, pp. 619-623, Jun. 2013.

[14] R. Martinez, P. N. Enjeti, “ A High-Performance Single -Phase Rectifier with Input Power Factor Correction," IEEE Trans. Power Electron., vol. 11, no. 2,pp. 311-317, Mar. 1996. 